\title{
Working With the Cultures of Canada in the ESL Classroom: A Response to Robert Courchêne
}

\section{Virginia Sauvé}

I am exceedingly glad to see Courchêne's comprehensive and courageous attempt to deal with a most difficult topic: the place of culture in the ESL classroom. A great deal of thought and work went into the preparation of his article, and I am personally grateful, for it has raised a number of productive and important questions for all of us to consider. In addition, he has provided us with some theoretical models that, regardless of our agreement or disagreement thereon, at least give us some starting places for discussion.

Although I agree with the need to attend to culture in our ESL curricula, like Courchêne I find it highly problematic in a number of ways. Some of these problems the author has addressed; others he did not. Rather than critique the document from start to finish, I prefer to write in a manner that adds to the discussion Courchêne has opened in the hope that it will stimulate the reader to do likewise, for the topic is an important one for any educator who is serious about viewing our work in a critical manner.

I see the problems with teaching culture in the Canadian ESL classroom as follows.

\section{There is a problem of naming "a Canadian culture."}

First of all, there is the old problem of discussing culture at all, which Edward Hall (1973) put so well for us. He describes three different layers of culture: primary, secondary, and tertiary. The first by definition resides in our unconscious where we cannot access it in order to discuss it; the second is reserved for discussion with fellow members of our culture; and the third is the set of customs, values, and so forth that we most commonly think of when we talk about culture. So how possible is it to teach something when we cannot even be fully conscious of it? I am comfortable with the notion of enabling the acquisition of culture; I am less comfortable with the idea of trying to teach it.

I am also unconvinced that one can talk about Canadian culture outside of particular contexts. The initial schemata of categories with which Courchêne suggests we develop appropriate cultural content would be flawed any time one attempted to move it from one context to another. (I could not myself identify with many of his examples as they were not part of my experience, particularly those from the French-Canadian experience.) Those referents and unspoken rules of behavior that we loosely call culture 
vary according to region, age, gender, ethnicity, class, race, rural versus urban locale, and work, to name some of the variables at play.

Therefore, to discuss how we might teach Canadian culture, I think we must situate our thoughts within a larger discussion in education, that of delivery modes of information sharing versus process modes of knowledge sharing and creation. I believe that Courchêne is well aware of this distinction, and it is important that we all become so. Until now, most ESL teachers I know do teach culture in the classroom, but most do it in a delivery mode that precludes attention to the relevance of our personal understandings and experiences of cultural ways to the learner's ability to access our contexts and therefore make use of the information we have presented.

In a recent team writing project in which I was involved, five white, middle-class, well-educated ESL teachers strove to create a chapter of cultural do's and don'ts for inclusion in a settlement workbook for newcomers in Alberta. After much frustration and hard work, we finally gave up and decided to leave it out for we could never agree on what we wanted to present. We discovered that, for all we had in common, we had major differences in our understandings of what was appropriate and inappropriate in the most common of situations: what time to arrive for dinner, when to start eating, gift-giving, and so forth. We could never get more than three of us to accept anything. Rather than try to impose a set of compromises on our materials and therefore on our learners, we agreed to disagree and to recommend to teachers that when they share their own personal views on cultural do's and don'ts, they be sure to advise their students that there are many different and equally acceptable ways of doing things depending on the context.

I liked that part of the Morasse consciousness-raising model Courchêne gives us in which new residents are asked to go out and observe the behavior of Canadians and then reflect on it as a group and talk about it in the classroom. Although it would be totally unrealistic to do this in many of our short-term ESL contexts, at the same time it respects that the real world of contact our learners have is often very different from the real world in which we live as educators. It respects the right and ability of the learner to perceive and learn from those perceptions rather than accept at face value whatever information we present, only to have it contradicted by other native Englishspeaking Canadians they meet.

I believe we always have to talk about culture in relation to a particular context. Therefore, when we are teaching a particular group of individual immigrants, we must be mindful of the most common contexts in which they are living and working and do our best both to elicit as much information from the group as possible and gather as much information from whatever sources we can to ensure that we ourselves are informed about the realities of the learners we teach. 
Our teacher education programs have not prepared us well to teach cultural aspects of Canadian life.

ESL as a theoretical body has grown out of applied linguistics and has therefore placed a disproportionate emphasis on the structure of language and theories of language acquisition. This has been done at the cost of developing the historical, political, and economic understandings that would have served us well in coming to understand better the various groups of learners we teach. Our teacher education programs might consider adding coursework in history, political science, economics, critical pedago$\mathrm{gy}$, and antiracist education as well as conflict resolution and other practical strategies for working with multicultural groups.

In addition, we need to learn how to develop process curricula that can be readily adapted to various contexts. What works with a group of well-educated European newcomers can be a dismal flop when working with those who have never had the opportunity to become literate in their mother tongue. What works with international students who have come to study English for a year and then return home will not work with refugees who are trying to deal with the shattering impact of war and terror in their lives and the lives of their families. We have accepted with relatively little resistance those programs and materials that imply that language learning is about content and that everyone needs the same thing. We know that is not true, but few of us know with confidence what alternatives we have.

It has been useful to me to have had the opportunity to work with educators who place a high value on reflecting on our own experiences as learners: what worked and what did not, what empowered us as free-thinking, creative individuals and what handicapped us into accepted traditional ways of being that limited us. Traditional teacher preparation programs have given teachers techniques, but no opportunity to develop the critical thinking skills to know when such techniques are appropriate and when they are not. They have not enabled us to develop the skills to look at materials and know which ones are appropriate for which learners and which are appropriate for no one. They have given us neither the courage nor the skill to consider developing quality materials of our own for use in the particular programs in which we teach, programs that are always changing as the populations who study in them are changing. They have not given us the ability to see those aspects of our own society that operate to maintain power for one group of people while continuing to exploit other groups. As Courchêne has said, how can we teach what we ourselves do not know? Our teacher preparation programs are in need of open evaluation, as are the programs in which they are preparing teachers to teach.

We must also provide many more opportunities for ongoing professional development in which our teachers can learn about the lives of new groups of incoming newcomers, about the languages they speak, and how those 
languages "see" the world, the cultures in which they have lived, the experiences they have endured, the health issues they have, and the work opportunities available to them here at this time.

There is a conceptual problem to be found in defining the work we do as ESL rather than something broader.

By calling the work we do ESL rather than settlement education, much of the most important work we do with learners is done either as an aside or even apologetically. ESL teachers are the frontline Canadians from whom immigrant newcomers get their picture of who and what Canadians are. From us they learn to see Canada through our eyes to some extent; they learn how to access essential services; and they learn what at least some Canadians expect of them. From us they hope (even when they do not expect) to learn what it takes to find a decent job in Canada. They accept what we offer even when it is not at the top of their priority list because they see no choice. It would be of great service to many immigrant newcomers to expand the notion of ESL and start offering programs in settlement education in which English was the medium of instruction rather than the sole legitimate end thereof. By doing this, along with replacing delivery-based understandings of education by process-based understandings in which learners were partners in knowledge creation, I believe we could make much better use of the limited time we have with many newcomers, especially refugees and those untrained in traditional methods of schooling.

Many of Courchêne's ideas require ESL educators to know more than they do now, yet in the politics of ESL in Canada at this time we see a decline in the valuing of the ESL professional.

In the past five years we have seen a serious undermining of the profession of ESL teaching in this country, a condition that can be directly tied to the implementation of LINC (Language Instruction for Newcomers to Canada, a federal funding program). Before LINC, most ESL was done in institutions and most staff were required to have professional certification and were paid, in most cases, professional salaries commensurate with their experience and credentials. With LINC came a swing away from the institutions toward funding increasing numbers of low-cost alternatives offered by settlement agencies, private schools, and special interest groups. These organizations were not required to have the same credentials, and even when they do the staff cannot be paid benefits nor do they receive salaries or wages in keeping with their training and the work they are doing. Extreme pressure has been exerted on such organizations to present proposals that are "cost-effective," which everyone quickly learns means cheaper than the institutions and cheaper than other providers. The standards have fallen. Although many positive things are to be said about LINC policy, its treatment of the ESL professional is anything but positive, and unless the current settlement 
renewal process takes this problem into account, we will only see this situation deteriorate even further.

The implications of this situation for teaching culture in the Canadian classroom, if we are to account for the changes in teacher preparation that Courchêne recommends and that would indeed be needed, are that the money would not be there to make it happen. Nor can teachers be expected to pursue graduate work on their own as they have in the past when they are being paid for 6.5 hours a day even though they are working 8-10 and being paid wages below those of their colleagues in other content areas.

We need to consider the role of immigrant educators on our ESL staffs.

At this time, there are relatively few immigrant educators on the staffs of most ESL programs. To be sure many have one or two individuals and most of those have gone through the same kinds of training programs as their native-born colleagues. I believe, however, that it would be advantageous for us to begin to explore more creative ways of involving immigrant educators in the provision of settlement programs for a number of reasons. First, they have had experiences we lack: they can bring a necessary dose of reality not only to their students in the classroom, but also to the rest of us in the staffrooms. Second, they bring a kind of credibility to the classroom that we can never bring.

My Ethiopian colleague and I can say exactly the same thing to a group of students, but they will hear it differently from each of us. She is black and I am white. She has been a refugee and I have not. She has worked her way through a variety of entry-level employment situations prior to coming into the classroom, whereas I have largely come through the system so to speak. In some cases, her background works to her advantage. In other cases, my background works to mine in terms of credibility. What works best of all is when the students hear the same thing from us both. I am their stereotypical Canadian and therefore credible when they are looking for things "Canadi$\mathrm{an}^{\prime \prime}$; she is one of them and therefore credible when they are looking for someone to identify with their experiences and give them realistic advice from that perspective.

If we want to teach culture from a dynamic perspective that allows immigrant newcomers to value their own ways and make informed choices based on knowledge of a number of different contexts in this country, it behooves us to consider ways of teaching that involve both immigrant and nonimmigrant educators working together to examine Canadian culture critically and openly.

We live in a society that sees itself as multicultural while continuing to be biased in favor of white, Anglo-Saxon, Christian, middle-class traditions and values. This contradiction that most Canadians so readily accept is highly problematic when one wishes to address the place of culture in ESL class- 
rooms. It is problematic in terms of knowing which version of culture to teach in which context and which to omit. It is problematic in terms of preparing people for the real world of work into which they most often go when they finish our programs. The rules that apply for the dominant majority are in many cases different from the unwritten rules laid on those who are nonwhite. We can argue until we are blue that this is not true, but why is it, if it is not true, that the majority of our service workers in the hospitality industry are immigrant workers of color, as are the sewing machine operators and factory workers, whereas the majority of well-paid positions of power in this society (elected representatives, lawyers, doctors, bankers, and other professionals) are white and more often than not male? Although it is appropriate to teach those who are "cast" for power in this society to be assertive, for example, that same behavior if taught to one who will only access entry-level jobs would be considered inappropriate in some situations and, for the person not well-briefed on the distinction, could cost him or her a job.

I am not defending this situation; on the contrary, I find it depressing, and I hope we will find ways of changing it. I am not suggesting that we teach immigrants of color to be passive, far from it. However, we can also not pretend that everyone is treated equally when everyone is not. What I am saying is that we have to learn to see our own society in a critical light and be willing to consider what the inequities might mean for immigrant newcomers; we have to be willing to work with our learners to find the most appropriate ways of overcoming such inequities. Women cannot use male behavior to accomplish the same ends as their male colleagues or they are called aggressive bitches and get nowhere. In the same manner that gender is a consideration in the classroom, or needs to be, race is also a consideration, and so we need educators of different races working together in the classroom to find appropriate and effective ways to overcome the barriers to equity that nonwhite learners experience when they leave our classrooms.

Due to the current fiscal climate of restraint and reprioritizing, our timelines are tighter than ever and we must reexamine all our priorities in the ESL classrooms of the nation.

This goes back to earlier comments I have made concerning the politics of ESL. Never have we been expected to accomplish so much with so little. Wages have been frozen. Hours have been cut. Budgets have been slashed and slashed again. If we are to add something to our curriculum, it stands to reason that something already there must be omitted. At least, that is true if we see curriculum as content.

Whatever changes we make to our curriculum and to our teacher preparation programs, they must be made in the light of the hard realities of today's economic climate. If an immigrant has only one year, or five months, 
for example, it is important to that person that programs respond to real needs and real circumstances. Many of our learners are frustrated and angry at what we teach in the classroom if it does not correspond to their priorities, which often have to do with finding work and caring for families. They need to know how to deal with racism when it occurs. They need to know how to deal with injustice in the workplace when it happens. They need to know how to solve health problems that threaten to commit their lives to the misery of social assistance forever. They need to know how to understand their children when they come home with ideas and behaviors that are totally foreign to everything they have ever known. In this sense they need to understand the impact of Canadian culture on their day-to-day lives. They cannot be "taught" culture from a static viewpoint. Rather, they need to be engaged in a process of discovering how Canadians see the world, how they themselves are seen by Canadians, and how they can increase the amount of power they have over their own lives in this new country. If this is what we mean by teaching culture in the classroom, then I am all for it. I only hope that this quest does not become a chapter at the end of the ESL workbook in the way we were taught French as children.

Culture is not about content. It is about the making and remaking of relationships in our society. It is about the kind of knowledge that gives us access or leaves us on the outside. Thank you, Robert Courchêne, for opening up this can of worms. It is a subject in need of our attention.

\section{The Author}

Virginia Sauvé is the founder and director of English Language Professionals, Edmonton. She is a well-known educator who advocates on behalf of immigrant rights. In addition to several other publications, Dr. Sauvé has written a Canadian citizenship reader, to be published by Oxford later this year.

\section{Reference}

Hall, E.T. (1973). The silent language. New York: Anchor Books. 